\title{
VEGETABLE FARMER BEHAVIOR ANALYSIS IN PURCHASING INSECTICIDES (Case Study In Vegetable Farmers in Sungai Selamat Siantan Hilir District)
}

\author{
Warganda ${ }^{(1)}$ Erlinda Yurisinthae ${ }^{(2)}$ Radian $^{(2)}$ \\ (1) Student of Magister Manajemen Agrisbisnis \\ (2) Lectures of The Faculty of Agriculture Tanjungpura University
}

\begin{abstract}
Vegetable Farmer Behavior Analysis in Purchasing insecticides (Case Study In Vegetable Farmers in Sungai Selamat Siantan Hilir District)

The objectives of this study were: 1) determine the behavior of vegetable farmers in the purchase of insecticides based on product attributes in Sungai Selamat Siantan Hilir District and 2) identify the product attributes that taken into consideration in the purchase of insecticide.
\end{abstract}

The research was conducted on vegetable farmers in the Sunagi Selamat Siantan hilir district North Pontianak within sampling by simple random sampling. Observed variables are variables which consists of consumer behavior and beliefs purchase evaluation based insecticide product attributes that include price, quality, volume and packaging manufacturer's instructions indicated on the package label. It also investigated behavior is also influenced by external factors which include variable normative beliefs and motivation variables. Analysis of research data using the model of Fishbein multiatribut.

Fishbein multi-attribute analysis results indicate that the value of a vegetable farmer attitudes to insecticide products is good on all three insecticides used are derived from the manufacturer Syngenta, Dupont and DGW. Quality attributes against insect pests of the class to be a major consideration in the purchase of the three insecticides.

Keywords: Consumer Behavior, Vegetable Farmers, Purchasing insecticides.

\section{PENDAHULUAN}

Penyediaan dan peningkatan produksi sayuran dihadapkan pada beberapa kendala, yaitu kendala fisik, biologi dan sosial ekonomi. Beberapa contoh yang menjadi kendala biologis adalah oganisme yang dapat menurunkan kualitas, produksi dan gagal panen, seperti hama, gulma dan penyakit.

Salah satu sarana pertanian yang dapat menanggulangi kendala biologis adalah insektisida. Seiring dengan perkembangan pertanian bangsa Indonesia menyebabkan perkembangan penggunaan insektisida terus meningkat dan diikuti oleh semakin banyaknya perusahaan yang memproduksi insektisida ditunjukkan semakin banyaknya jenis dan merek insektisida yang ada di pasaran.

Mengingat semakin banyaknya jenis produk dan brands imsektisida yang beredar di pasaran, maka menimbulkan persaingan dagang juga semakin tinggi. Perusahaan yang bergerak dalam Chemical Industries perlu menentukan strategi pemasaran yang tepat sehingga produk yang ditawarkan dapat memenuhi kepuasan konsumen.

Faktor yang paling dominan dan biasanya terdapat pada setiap perilaku konsumen antara lain adalah kepercayaan yang merupakan semua pengetahuan yang dimiliki konsumen dalam semua kesimpulan yang dibuat konsumen tentang obyek, atribut serta manfaatnya dan sikap yang merupakan perasaan atau terhadap sebuah rangsangan, yang mana pada akhirnya akan membentuk suatu perilaku konsumen. 
Perilaku konsumen terhadap suatu produk berbeda antara yang satu dengan yang lainnya. Konsumen yang membeli pestisida mempunyai alasan yang bervariasi. Selera konsumen yang bervariasi ini mendorong pengusaha produk berupaya untuk memenuhi keinginan konsumen dan mempertahankan konsumen agar selalu menyukai dan membeli produk tersebut. Hal yang paling menentukan perilaku konsumen sebelum memutuskan untuk membeli suatu produk yaitu apakah konsumen menyukai produk tersebut atau tidak. Konsumen dapat menyukai suatu produk apabila konsumen sudah memiliki pengetahuan tentang produk tersebut sehingga menimbulkan kepercayaan pada suatu produk itu sendiri.

Perusahaan perlu memperhatikan perilaku konsumen sebagai upaya memperbaiki produk dan strategi pemasaran agar produk yang ditawarkan dapat diminati oleh konsumen. Hal ini tidak hanya untuk membantu penjual menghadapi persaingan, tetapi juga membantu mereka agar dapat memasarkan produk yang dihasilkan dengan lebih efektif dan dapat mempertahankan pangsa pasar yang mereka miliki.

Berdasarkan uraian di atas, maka perlu dilakukan kajian untuk mengetahui bagaimana perilaku konsumen terhadap penggunaan pestisida yang akan mempengaruhi proses keputusan pembelian mereka. Penelitian ini dilakukan di Sungai Selamat kelurahan Siantan Hilir Kecamatan Pontianak Utara Pontianak.

Masalah penelitian dirumuskan sebagai berikut:

1. Bagaimana perilaku petani sayuran terhadap beberapa atribut produk dalam keputusan pembelian insektisida di Sungai Selamat Kelurahan Siantan Hilir.

2. Atribut apa saja yang menjadi pertimbangan dalam pembelian dan penggunaan insektisida untuk tanaman sayuran.

\section{METODE PENELITIAN}

Penelitian ini dilakukan di Sungai Selamat Kelurahan Siantan Hilir Kecamatan Pontianak Utara Pontianak. Waktu penelitian ini dilaksanakan pada awal November 2012 - Juli tahun 2013.

Populasi dalam penelitian ini adalah petani sayuran yang membeli dan menggunakan pestisida untuk usahataninya. Teknik pengambilan sampel pada penelitian ini adalah sampling acak sederhana (simple random sampling) yaitu pengambilan sampel dari anggota populasi secara acak. Jumlah petani (responden) dalam penelitian ini tercatat 60 petani. berikut :

Variabel yang akan diteliti pada penelitian ini meliputi empat variabel yaitu sebagai

\section{a. Variabel Keyakinan Membeli dan Variabel Evaluasi}

Merupakan tanggapan konsumen sebelum membeli dimana keyakinan adalah kekuatan kepercayaan bahwa sesuatu produk memiliki atribut tertentu.

Sedangkan evaluasi adalah tanggapan konsumen setelah membeli atau menggunakan.

Teknik pengukurannya adalah dengan memberikan skor pada masing-masing komponen yang dinilai dengan kategori sebagai berikut :
Sangat Baik (SB)
diberi skor 5, Baik ( B) diberi skor 4
Cukup Baik (CB)
diberi skor 3, Tidak Baik (TB) diberi skor 2 
Sangat Tidak Baik (STB) diberi skor 1.

Variabel keyakinan membeli dan variabel evaluasi memiliki komponen/atribut produk yang sama yaitu : 1) harga (V1), 2) kualitas/daya bunuh (V2), 3) volume kemasan (V3) dan 4) Aturan pakai (V4).

b. Variabel Keyakinan Normatif dan Variabel Motivasi

Variabel keyakinan normatif merupakan pengaruh orang lain dalam membeli produk dan variabel motivasi merupakan motivasi membeli oleh pengaruh orang lain.

Teknik pengukurannya adalah sebagai berikut :

$$
\begin{array}{lll}
\text { Sangat Percaya (SP) } & \text { diberi skor } & 5 \text {, Percaya (P) diberi skor } 4 \\
\text { Cukup Percaya (CP) } & \text { diberi skor } & 3 \text {, Tidak Percaya (TP) diberi skor } 2 \\
\text { Sangat Tidak Percaya (STP) diberi skor } & 1 .
\end{array}
$$

Variabel keyakinan normatif dan variabel motivasi memiliki komponen yang sama yaitu : 1) peran Anggota keluarga, 2) peran teman dan 3) peran tenaga penjual.

Data yang diperoleh dikelompokan sesuai dengan jumlah pemilik tiap atribut dan diolah sehingga menghasilkan tabel - tabel. Tiap pertanyaan diberi skala interval yang masing - masing diberi nilai skor dari 1 sampai 5 . Skala interval dari 1 sampai 5 dipilih agar responden/ konsumen dapat memberikan jawaban yang lebih spesifik.

Pengujian hipotesis pertama dilakukan dengan analisis multi atribut Fishbein hingga diperoleh nilai $B$, selanjutnya dilakukan kategorisasi nilai perilaku. Hipotesis kedua diuji dengan analisis multi atribut yaitu hasil perkalian total responden dengan nilai skor pada masing-masing atribut produk.

Menurut Mowen dan Minor ( 2001 ), dalam penelitian ini alat analisis yang dapat digunakan adalah analisis model multi atribut yaitu sebagai berikut :

- Model Sikap Fishbein :

$\mathrm{n}$

$$
\begin{gathered}
A B=\sum\left(b_{i}\right)\left(e_{i}\right) \\
i=1
\end{gathered}
$$

Dimana :
$\mathrm{AB}=\quad$ Sikap total individu terhadap obyek tertentu
$\mathrm{b}_{\mathrm{i}} \quad=\quad$ Kekuatan keyakinan konsumen bahwa objek memiliki atribut $\mathrm{i}$
$\mathrm{e}_{\mathrm{i}} \quad=\quad$ Evaluasi kepercayaan individu mengenai atribut $\mathrm{i}$
$\mathrm{n}=\quad$ Jumlah kriteria atribut yang relevan

- Model Maksud Perilaku

$\mathrm{B} \sim \mathrm{B} 1=\mathrm{w}_{1}(\mathrm{AB})+\mathrm{w}_{2}(\mathrm{SN})$

Dimana :

$\begin{array}{lll}\mathrm{B} & = & \text { Perilaku } \\ \mathrm{B} 1 & = & \text { Maksud perilaku }\end{array}$




$$
\begin{array}{lll}
\mathrm{AB} & = & \text { Sikap terhadap pelaksanaan perilaku } \mathrm{B} \\
\mathrm{SN} & = & \text { Norma subjektif } \\
\mathrm{W}_{1}, \mathrm{~W}_{2} & = & \text { Bobot yang ditentukan secara empiris yang } \\
& & \begin{array}{l}
\text { menggambarkan pengaruh relatif dari } \\
\text { komponen }
\end{array}
\end{array}
$$

- Mencari Nilai SN ( Norma Subjektif )

$$
\mathrm{SN}=\underset{\substack{n \\ \mathrm{j}=1}}{\left(\mathrm{NB}_{\mathrm{j}}\right)\left(\mathrm{MC}_{\mathrm{j}}\right)}
$$

Dimana :

SN $\quad=\quad$ Norma Subjektif

$\mathrm{NB}_{\mathrm{j}}=\quad$ Keyakinan normative individu

$\mathrm{MC}_{\mathrm{j}} \quad=\quad$ Motivasi konsumen

$\mathrm{n} \quad=\quad$ Banyaknya referen yang relevan

Bobot $W_{1}$ dan $W_{2}$ dapat ditentukan dengan cara sebagai berikut :

$$
W_{1}=\frac{G M A B}{G M A B+G M S N} \quad W_{2}=\frac{G M S N}{G M A B+G M S N}
$$

Dimana

GM AB $=\frac{\text { Total } b_{i}+\text { Total } e_{i}}{2 \times \text { jlh. Atributnya }} \quad$ GM SN $=\frac{\text { Total NB }+ \text { Total } \mathrm{MC}_{j}}{2 \times \text { Jlh. atributnya }}$

Keterangan :

$\mathrm{GM} \mathrm{AB}=$ Grand Mean Nilai Sikap

GM SN = Grand Mean Nilai Norma Subjektif

Dengan kriteria keputusan sebagai berikut :

Jika $B>0$, maka perilaku konsumen yang terbentuk adalah baik,

Jika $B=0$, maka perilaku konsumen yang terbentuk adalah netral

Jika $\mathrm{B}<0$, maka perilaku konsumen yang terbentuk adalah tidak baik.

\section{HASIL DAN PEMBAHASAN}

Nilai sikap konsumen didapat dengan mengalikan rata-rata nilai variabel tingkat keyakinan (bi) dengan rata-rata nilai variabel evaluasi (ei), sehingga didapat nilai total (bi $x$ ei) yang merupakan nilai sikap konsumen keseluruhan.

Kategori nilai sikap konsumen didapatkan dari hasil perkalian dari skala skor, yaitu : sangat baik $(S B)=5$, baik $(B)=4$, cukup baik $(C B)=3$, tidak baik $(T B)=2$, sangat tidak baik $(\mathrm{STB})=1$ dengan nilai tingkat evaluasi konsumen (ei). 
Tabel 1. Nilai Total Sikap Konsumen

\begin{tabular}{clccc}
\hline & Produsen Insektisida & Syngenta & DuPont & DGW \\
\hline No. & Atribut & (bi x ei) & (bi x ei) & (bi x ei) \\
\hline 1 & Harga & 14,35 & 10,24 & 9,79 \\
2 & Kualitas & 15,70 & 18,68 & 16,47 \\
3 & Volume & 9,61 & 9,82 & 9,27 \\
4 & Aturan Pakai & 13,39 & 17,85 & 16,24 \\
\hline \multicolumn{2}{c}{ Total } & 53,05 & 56,59 & 51,77
\end{tabular}

Sumber : Analisis data penelitian, 2012

Berdasarkan tabel di atas nilai sikap konsumen adalah sebagai berikut :

a. Pada nilai total sikap konsumen (tabel 1), pada produk dari Syngenta, DuPont dan DGW atribut harga mendapat nilai masing-masing 14,35 yang berada pada interval 16,40 dan 12,30 untuk Syngenta, untuk DuPont 10,24 yang berada pada interval 13,08 dan 9,81 serta untuk DGW atribut harga, nilai sikapnya adalah 9,79 yang berada pada interval 12,12 dan 9,09. Ketiga produk tersebut konsumen memiliki tanggapan yang baik terhadap harga yang ditawarkan.

b. Pada nilai total sikap konsumen (tabel 1), pada produk dari Syngenta, DuPont dan DGW atribut kualitas mendapat nilai masing-masing 15,70 yang berada pada interval 16,40 dan 12,30 untuk Syngenta, Untuk DuPont 18,68 yang berada pada interval 17,88 dan 13,41 serta untuk DGW atribut kualitas, nilai sikapnya adalah 16,47 yang berada pada interval 17,20 dan 12,90. Konsumen memiliki tanggapan yang baik terhadap kualitas ketiga produk yang ditawarkan.

c. Pada nilai total sikap konsumen (tabel 1), pada produk dari Syngenta, DuPont dan DGW atribut volume kemasan produk mendapat nilai masing-masing 9,61 yang berada pada interval 12,52 dan 9,89 untuk Syngenta, Untuk DuPont 9,82 yang berada pada interval 12,80 dan 9,60 serta untuk DGW atribut kualitas, nilai sikapnya adalah 9,27 yang berada pada interval 12,08 dan 9,06. Konsumen memiliki tanggapan yang baik terhadap volume kemasan ketiga produk yang ditawarkan.

d. Pada nilai total sikap konsumen (tabel 1), pada produk dari Syngenta, DuPont dan DGW atribut aturan pakai pada label kemasan mendapat nilai masing-masing 13,39 yang berada pada interval 14,88 dan 11,16 untuk Syngenta, Untuk DuPont 17,85 yang berada pada interval 16,92 dan 12,69 serta untuk DGW atribut aturan pakai, nilai sikapnya adalah 16,24 yang berada pada interval 16,32 dan 12,24. Konsumen memiliki tanggapan yang baik dan mendekati sangat baik terhadap aturan pakai ketiga produk yang ditawarkan.

Rentang skor 5 sebagai sangat baik (SB) dan 1 sebagai sangat tidak baik (STB) dari masing-masing produk yaitu Syngenta, DuPont dan DGW maka rentang nilai maksimum sampai minimum adalah 75,25 sampai 15,05 untuk Syngenta, 75,85 sampai 15,17 untuk DuPont dan untuk DGW yaitu 72,15 sampai 14,43. Berdasarkan pendapat Sugiyono (1996) penilaian rentang skor dilakukan sesuai dengan kategori pertama antara skor tertinggi dan skor selanjutnya.

Sikap akan mempengaruhi konsumen untuk membeli suatu produk atau tidak membeli. Sikap positif pada produk tertentu akan memungkinkan konsumen melakukan pembelian terhadap produk itu. Berdasarkan skala di atas, total keseluruhan nilai sikap konsumen untuk Syngenta, DuPont dan DGW masingmasing mendapat nilai 53,05; 56,59 dan 51,77 (tabel 2) berada pada kategori baik. Kategori ini menggambarkan keyakinan dan pilihan konsumen dalam memilih dan 
membeli produk insektisida dari beberapa produsen yang beredar di kota Pontianak.

Interpretasi dimaksudkan untuk menafsirkan pengertian dari nilai yang didapatkan dalam analisis. Sesuai dengan identifikasi peneliti mengenai sikap petani sayuran dalam pembelian insektida, maka dapat dijelaskan sebagai berikut :

a. Petani sayuran selaku konsumen insektisida dalam membeli produk insektisida tetap mempertimbangkan harga namun bukan menjadi pertimbangan utama.

b. Kualitas produk dapat menjadi kepercayaan bagi konsumen untuk membeli produk insektisida di manapun kios yang menjualnya serta menjadi pertimbangan utama.

Peningkatan kualitas dan inovasi yang baik dan berkelanjutan dari produsen akan dapat meningkatkan nilai sikap konsumen.

c. Volume dapat mendorong keputusan konsumen dalam membeli produk. Produk dengan kemasan volume yang besar tetapi dengan harga yang cukup mahal tetap diminati, walupun keputusan membeli konsumen terhadap atribut volume pada ketiga produk tidak signifikan.

d. Aturan pakai merupakan label pada kemasan yang berguna bagi konsumen sebagai petunjuk dalam penggunaan produk. Semakin jelas petunjuknya semakin memudahkan konsumen menggunakan produk tersebut, demikian sebaliknya.

Tabel 2. Interpretasi Nilai Sikap Konsumen

\begin{tabular}{llccc}
\hline \multicolumn{5}{c}{ Produsen : Syngenta } \\
\hline No. & & Nilai Sikap & Nilai Ideal Sikap & Kategori \\
\hline 1 & Harga & 14,35 & 20,50 & Baik \\
2 & Kualitas & 15,70 & 20,50 & Baik \\
3 & Volume & 9,61 & 15,65 & Baik \\
4 & Aturan Pakai & 13,39 & 18,60 & Baik \\
\hline \multicolumn{4}{c}{} \\
\hline 1 & Harga & Produsen : DuPont & Baik \\
2 & Kualitas & 10,24 & Baik \\
3 & Volume & 18,68 & 16,35 & Baik \\
4 & Aturan Pakai & 9,82 & 22,35 & Baik \\
\hline & & 17,85 & 16,00 & Baik \\
\hline 1 & Harga & 21,15 & Baik \\
2 & Kualitas & 9,79 & Baik \\
3 & Volume & 16,47 & 15,15 & Baik \\
4 & Aturan Pakai & 9,27 & 21,50 & 15,10 \\
\hline
\end{tabular}

Sumber : Analisis data penelitian, 2012

Keyakinan Normatif (NBj) merupakan pengaruh orang lain terhadap konsumen dalam pembelian produk. Dari tabel di atas terdapat tanggapan responden dari indikator keyakinan normatif yaitu :

SP (Sangat Percaya) diberi skor 5, P (Percaya) diberi skor 4

CP (Cukup Percaya) diberi skor 3, TP (Tldak Percaya) diberi skor 2

STP (Sangat Tidak Percaya) diberi skor 1.

Jumlah masing-masing tanggapan atas atribut dikalikan dengan skor dari setiap tanggapan sehingga diperoleh rata-rata. 
Data tabel 3, peran teman memiliki pengaruh yang terbesar yaitu dengan jumlah 276 dengan rata-rata 4,60 untuk produk Syngenta dan DGW, dengan total 280 dengan rata-rata 4,67 untuk DuPont. Hal ini menunjukkan bahwa petani sayuran sebagai konsumen insektisida sebagian besar lebih terpengaruh kepada teman kemudian diikuti oleh keluarga dan tenaga penjual.

Tabel 3. Tanggapan Responden dari Indikator Keyakinan Normatif

\begin{tabular}{llcccccc}
\hline \multicolumn{2}{c}{ Produsen Insektisida } & \multicolumn{2}{c}{ Syngenta } & \multicolumn{2}{c}{ DuPont } & \multicolumn{2}{c}{ DGW } \\
\hline No. & Indikator & Jumlah & $\begin{array}{c}\text { Rata-rata } \\
\text { (NBj) }\end{array}$ & Jumlah & $\begin{array}{c}\text { Rata-rata } \\
(\mathrm{NBj})\end{array}$ & Jumlah & $\begin{array}{c}\text { Rata-rata } \\
(\mathrm{NBj})\end{array}$ \\
\hline 1 & Peran Keluarga & 208 & 3,47 & 221 & 3,68 & 208 & 3,47 \\
2 & Peran Teman & 276 & 4,60 & 280 & 4,67 & 276 & 4,60 \\
3 & Peran Penjual & 192 & 3,20 & 194 & 3,23 & 194 & 3,23 \\
\hline
\end{tabular}

Sumber : Analisis data penelitian, 2012

Tingkat Motivasi (MCj) merupakan kemungkinan konsumen termotivasi untuk membeli produk. Dari penelitian yang dilakukan, hasil yang diperoleh dapat dilihat pada tabel berikut :

Tabel 4. Tanggapan Responden dari Indikator Motivasi

\begin{tabular}{llcccccc}
\hline \multicolumn{2}{c}{ Produsen Insektisida } & \multicolumn{2}{c}{ Syngenta } & \multicolumn{2}{c}{ DuPont } & \multicolumn{2}{c}{ DGW } \\
\hline No. & Indikator & Jumlah & $\begin{array}{c}\text { Rata-rata } \\
(\mathrm{MCj})\end{array}$ & Jumlah & $\begin{array}{c}\text { Rata-rata } \\
(\mathrm{MCj})\end{array}$ & Jumlah & $\begin{array}{c}\text { Rata-rata } \\
(\mathrm{MCj})\end{array}$ \\
\hline 1 & Peran Keluarga & 213 & 3,55 & 223 & 3,72 & 213 & 3,55 \\
2 & Peran Teman & 280 & 4,67 & 282 & 4,70 & 277 & 4,62 \\
3 & Peran Penjual & 194 & 3,23 & 198 & 3,30 & 197 & 3,28 \\
\hline
\end{tabular}

Sumber : Analisis data penelitian, 2012

Analisis data tersebut menunjukkan tanggapan responden dari indikator motivasi seperti pada keyakinan normatif di atas. Jumlah masing-masing tanggapan atas atribut dikalikan dengan skor dari setiap tanggapan sehingga diperoleh rata-rata.

Peran teman menjadi motivasi terbesar bagi konsumen, yaitu masing-masing dengan jumlah 280 dengan rata-rata 4,67 untuk produk Syngenta, produk DuPont dengan jumlah 282 dengan rata-rata 4,70 dan produk DGW dengan jumlah 277 dengan rata-rata 4,62 . Nilai Norma suyektif konsumen diperoleh dengan mengalikan rata-rata nilai variabel keyakinan normatif (NBj) dengan rata-rata nilai variabel motivasi $(\mathrm{MCj})$, sehingga nilai total $(\mathrm{NBj} \times \mathrm{MCj}$ ) yang merupakan nilai norma subjektif konsumen (SN) seperti tersaji pada tabel 5 .

Tabel 5. Nilai Norma Subjektif Konsumen

\begin{tabular}{llccc}
\hline & Produsen Insektisida & Syngenta & DuPont & DGW \\
\hline No. & \multicolumn{1}{c}{ Indikator } & $(\mathrm{NBj} \times \mathrm{MCj})$ & $(\mathrm{NBj} \times \mathrm{MCj})$ & $(\mathrm{NBj} \times \mathrm{MCj})$ \\
\hline 1 & Peran Keluarga & 12,32 & 13,69 & 12,32 \\
2 & Peran Teman & 21,48 & 21,95 & 21,25 \\
3 & Peran Penjual & 10,34 & 10,66 & 10,59 \\
\hline
\end{tabular}

Sumber : Analisis data penelitian, 2012 
Kategori nilai sikap didapatkan dari hasil perkalian dari skala skor, yaitu :

Sangat percaya $(S P)=5$, percaya $(P)=4$, cukup percaya $(C P)=3$, tidak percaya $(T P)=$ 2 , sangat tidak percaya $(\mathrm{STP})=1$ dengan nilai tingkat motivasi konsumen (MCj).

Berdasarkan nilai norma subjektif konsumen dapat dinterpretasikan yaitu :

a. konsumen percaya sampai sangat percaya bahwa teman dalam pengertian petani sayuran dalam hamparan atau kelompok tani mempunyai peranan dalam memotivasi konsumen dalam membeli produk insektisida.

b. konsumen percaya bahwa keluarga dalam pengertian anggota keluarga terdekat mempunyai peranan dalam memotivasi konsumen dalam membeli produk insektisida.

c. konsumen percaya bahwa tenaga penjual mempunyai peranan dalam memotivasi konsumen dalam membeli produk insektisida.

Total nilai norma subjektif konsumen secara keseluruhan (tabel 5) diperoleh nilai masing-masing 44,14 yang berada pada interval 45,80 dan 34,45 untuk Syngenta, 46,30 yang berada pada interval 46,88 dan 35,16 untuk DuPont dan untuk DGW dengan total 44,14 yang berada pada interval 45,80 dan 34,45 . Hal ini berarti konsumen percaya bahwa peran keluarga, peran teman, peran orang lain mempunyai peranan dalam memotivasi konsumen dalam membeli ketiga produk insektisida.

Hasil identifikasi peneliti mengenai sikap petani sayuran dalam pembelian insektida, maka dapat dijelaskan bahwa konsumen cukup besar dipengaruhi oleh lingkungan sekitarnya. Keputusan pembelian dipengaruhi oleh lingkungan sosialnya dalam hal ini peran teman lebih menonjol dibanding keluarga dan tenaga penjual. Pengaruh yang muncul dari lingkungan sosial konsumen tersebut antara lain dalam bentuk budaya, kelas sosial, keluarga dan kelompok acuan.

Menurut Setiadi (2003), kelompok mempengaruhi proses pembelian yang dibuat oleh seorang konsumen. Kelompok dijadikan acuan oleh konsumen sebagai dasar untuk perbandingan atau referensi dalam memberikan standar dan nilai yang akan mempengaruhi perilakunya. Selanjutnya Engel dkk. (1995) menekankan bahwa kelompok acuan (reference group) adalah orang atau kelompok yang mempengaruhi secara bermakna perilaku pribadi.

Kotler dan Amstrong (2001), efektivitas pengaruh kelompok acuan pada perilaku konsumen bervariasi, tergantung pada produknya dan tersedianya informasi tentang produk itu untuk konsumen. Semakin sedikit informasi atau pengalaman seseorang terhadap produk tertentu, maka semakin kuat pengaruh kelompok rujukan terhadap produk dan orang tersebut. Pengaruh cenderung sangat kuat jika produk tersebut dilihat dari orang lain yang dihormati konsumen.

Perilaku konsumen dipengaruhi oleh kelompok rujukan dimana mereka menjadi anggota di dalamnya. Setiap kelompok juga mengembangkan rangkaian sikap dan kepercayaan sendiri yang bisa menjadi norma bagi perilaku anggotanya (Mangkunegara, 2001). Ditegaskan oleh Stanton (1996), bahwa pengaruh kelompok rujukan semakin besar pada perilaku konsumen dimana para anggotanya sering bertatap muka.

Setelah mendapatkan hasil dari pengukuran nilai sikap dan nilai norma subyektif maka selanjutnya dilakukan perhitungan nilai perilaku konsumen. Dari hubungan formula sikap dan norma subyektif akan dihasilkan hubungan model behavioral intention attribute Fishbein dari produk masing-masing sebagai berikut :

$$
\begin{aligned}
\mathbf{B} \sim \mathbf{B} & =\mathrm{W} 1(\mathrm{AB})+\mathrm{W} 2(\mathrm{SN}) \\
& =0,49(43,05)+0,51(44,14) \\
& =43,60 \text { (Syngenta) }
\end{aligned}
$$




$$
\begin{aligned}
\mathbf{B} \sim \mathbf{B} & =\mathrm{W} 1(\mathrm{AB})+\mathrm{W} 2(\mathrm{SN}) \\
& =0,49(56,59)+0,51(46,30) \\
& =51,34(\text { DuPont }) \\
\mathbf{B} \sim \mathbf{B} & =\mathrm{W} 1(\mathrm{AB})+\mathrm{W} 2(\mathrm{SN}) \\
& =0,489(51,77)+0,52(44,16) \\
& =48,28(\mathrm{DGW}) .
\end{aligned}
$$
bawah ini:

Kriteria nilai perilaku konsumen dianggap baik sampai tidak baik disajikan di Jika $\mathbf{B}>0$, maka perilaku konsumen yang terbentuk adalah baik.

Jika $\mathbf{B}=0$, maka perilaku konsumen yang terbentuk adalah netral.

Jika $\mathbf{B}<0$, maka perilaku konsumen yang terbentuk adalah tidak baik.

Nilai B (nilai perilaku konsumen) yang diperoleh masing-masing untuk Synegnta, DuPont dan DGW adalah 43,60; 51,34 dan 48,28. Oleh karena nilai B positif (lebih besar dari nol), maka berdasarkan kriteria keputusan di atas, dapat diinterpretasikan bahwa $\mathbf{B}$ adalah perilaku konsumen (petani sayuran) dalam pembelian insektida dari 3 produsen menunjukkan bahwa perilaku konsumen yang terbentuk terhadap produk insektisida tersebut berdasarkan atribut harga, kualitas/daya bunuh, volume kemasan dan aturan pakai pada label kemasan adalah baik.

Superioritas produk berdasarkan atribut yang ada pada produk tersebut yang tersaji pada nilai sikap konsumen, sehingga dapat lebih mudah dipahami kekuatan atribut pada setiap produk seperti tersaji pada tabel 6 .

Tabel 6. Nilai Keyakinan Membeli Ketiga Produk Berdasarkan Atribut Produk Insektisida

\begin{tabular}{clcccc}
\hline No & Produsen & Harga & Kualitas & Volume & Aturan Pakai \\
\hline 1 & Syngenta & 3,50 & 3,83 & 3,07 & 3,60 \\
2 & DuPont & 3,13 & 4,18 & 3,07 & 4,22 \\
3 & DGW & 3,23 & 3,83 & 3,07 & 3,98 \\
\hline
\end{tabular}

Sumber : Analisis data penelitian, 2012

Hasil analisis keyakinan setelah membeli (evaluasi) terhadap atribut produk insektisida dari tiga produsen tersaji pada tabel 7.

Tabel 7. Nilai Keyakinan Setelah Membeli dan Sikap Konsumen Terhadap Ketiga Produk Berdasarkan Atribut Produk Insektisida

\begin{tabular}{clccccc}
\hline No & Produsen & Harga & Kualitas & Volume & Aturan Pakai & Total Nilai Sikap \\
\hline 1 & Syngenta & 4,10 & 4,10 & 3,13 & 3,72 & 53,05 \\
2 & DuPont & 3,27 & 4,47 & 3,20 & 4,23 & 56,59 \\
3 & DGW & 3,03 & 4,30 & 3,02 & 4,08 & 51,77 \\
\hline
\end{tabular}

Sumber : Analisis data penelitian, 2012

Sedangkan rekapitulasi nilai perilaku konsumen (B) terhadap atribut yang ada dalam membeli produk insektisida disajikan pada tabel 8. 
Tabel 8. Nilai Perilaku Konsumen Terhadap Ketiga Produk Insektisida

\begin{tabular}{ccc}
\hline No & Produsen & Nilai Perilaku Konsumen (B) \\
\hline 1 & Syngenta & 43,60 \\
2 & DuPont & 51,34 \\
3 & DGW & 48,28 \\
\hline
\end{tabular}

Sumber : Analisis data penelitian, 2012

Interpretasi untuk membandingkan ketiga produk insektisida yang digunakan petani sayuran menunjukkan bahwa sebelum membeli dan setelah membeli produk tersebut terjadi peningkatan nilai. Hal ini berarti bahwa konsumen merasa puas dengan produk yang dipakai dan cenderung akan mengulangi pembeliaan produk dari waktu ke waktu.

Pertimbangan yang dijadikan pilihan sebelum membeli dan setelah membeli lebih dominan kualitas insektisida daripada atribut lain, walaupun untuk Syngenta memiliki nilai yang sama antara harga dan kualitas $(4,10)$. Petani di Sungai Selamat sudah mengusahakan usahatani sayurannya cukup lama dan menggunakan insektisida berulang-ulang dalam menjaga produksi sayurannya. Petani diduga enggan menggunakan produk lain yang dipersepsikan daya bunuhnya kurang baik dibanding produk yang dipakai saat ini. Faktor tidak bersedia menanggung resiko yang besar akibat kesalahan pengambilan keputusan dapat berdampak terhadap kerusakan tanaman sayuran yang diusahakan. Menghadapi resiko yang bakal timbul akibat kesalahan membuat keputusan, konsumen melakukan :

a) Mencari informasi selengkap mungkin.

b) Setia terhadap suatu merk

c) Memilih merk yang sudah terkenal terkenal

d) Membeli barang yang paling mahal

e) Mempercayakan kepada toko penjual.

Berkaitan erat dengan ketidakmampuan menganggung resiko yang bakal timbul, maka konsumen mempercayai produk yang sudah digunakan berkali-kali selama berusahatani dan memberikan kepuasaan atas produk yang dipakai. Proses Brand Loyalty terjadi ketika pilihan berulang, konsumen belajar dari pengalaman masa lalu dan membeli merek yang memberikan kepuasan dengan sedikit atau tidak ada proses pertimbangan dalam pengambilan keputusan. Loyalitas merek dapat muncul dari kepuasan pembelian yang lalu sehingga pencarian informasi dan evaluasi merek terbatas atau tidak penting keberadaannya dalam konsumen memutuskan membeli merek yang sama. Pemahaman ekspektasi konsumen dapat mempunyai dampak yang penting pada strategi harga, kadangkala harga diasosiasikan dengan kualitas. Beberapa ciri brand loyalty adalah commited buyer, likes the brand, statisfied buyer, habitual buyer dan switcher.

Stanton (1996) mengungkapkan bahwa perilaku konsumen terhadap kualitas berubah-ubah seiring dengan perubahan yang terjadi pada harga. Semakin tinggi harga suatu produk semakin tinggi pula kualitas produk yang dipersepsi oleh konsumen.

Berdasarkan nilai perilaku konsumen, produk DuPont menunjukkan nilai yang lebih tinggi dibanding dua produk lainnya. Atribut kualitas pada produk DuPont dalam menanggulangi hama pada sayuran oleh petani sayuran di Sungai Selamat sudah dipercaya konsumen. 


\section{PENUTUP}

\section{Kesimpulan}

Berdasarkan hasil penelitian dan analisis data yang telah dilakukan, dapat disimpulkan sebagai berikut :

1. Petani sayuran di Sungai Selamat Kelurahan Siantan Hilir cukup loyal dalam membeli insektisida terutama dari 3 produsen yaitu masing-masing Syngenta, DuPont dan Dharma Guna Wibawa.

2. Perilaku petani sayuran di Sungai Selamat Kelurahan Siantan Hilir dalam pembelian insektisida dikategorikan baik berdasarkan atribut yang yang melekat pada produk yaitu harga, kualitas/daya bunuh, volume kemasan dan aturan pakai yang tertera pada label kemasan.

3. Atribut yang dijadikan pertimbangan sebelum dan sesudah membeli produk insektisida dari 3 produsen yang berbeda berturut-turut adalah kualitas/daya bunuh, aturan pakai, harga dan volume kemasan.

4. Keputusan pembelian insektisida dari ketiga produk lebih dipengaruhi atau termotivasi oleh peran orang lain.

5. Berdasarkan nilai W1 dan W2, minat berperilaku konsumen tidak dapat diprediksi dari sikap konsumen.

\section{Saran}

1. Produsen dari insektisida yang digunakan petani sayuran saat ini agar tetap menjaga kualitas/daya bunuh dari produk insektisida dengan harga yang bersaing.

2. Dengan asumsi harga yang tetap, maka produsen perlu mencari inovasi baru dalam strategi pemasaran produknya agar petani tetap loyal (Brands Loyality) dan tidak berpindah ke produk lain dari produsen yang berbeda.

\section{DAFTAR PUSTAKA}

Engel, JS, RD. Black Well, TW. Miniard, 1995, Perilaku Konsumen, Jilid I dan Jilid II, Edisi keenam, Binarupa, Aksara, Jakarta.

Fishbein, M, 1967, A Behavior Theory Approach to the Rehitions Beliefs About and Object and the Attitude Toward the Object, in Martin Fishbein (ed), Reading Attitude Theory and Measurement, Wiley, New York.

Kotler, P. dan Amstrong, 2001, Dasar Dasar Pemasaran, Edisi Keenam, Intermedia, Jakarta.

Mangkunegara, Azwar, Babu, 2001, Perilaku Konsumen, Penerbit Refika Aditama, Bandung.

Minor, M, dan JC. Mowen.2001. Perilaku Konsumen Jilid I, Penerbit Erlangga, Jakarta.

Setiadi,NJ,2003, Perilaku Konsumen, Prenada Media, Jakarta.

Stanton, W.J., 1996, Prinsip Pemasaran, edisi 7 Jilid 1, Penerbit Erlangga, Jakarta. 